\title{
Mickey Mouse como símbolo de resistencia contra la contaminación cultural: una aproximación a la obra Chac Mool III de Nadín Ospina
}

\section{Artículo de Reflexión}

\section{Albeiro Arias}

Universidad del Tolima, Ibagué, Colombia albeiroarias@ut.edu.co

Recibido: 15 de agosto de 2017 Aprobado: 20 de mayo de 2018

Cómo citar este artículo: Arias, Albeiro (2018). Mickey Mouse como símbolo de resistencia contra la contaminación cultural: una aproximación a la obra Chac Mool III de Nadín Ospina. Calle 14: revista de investigación en el campo del arte 13 (24) pp. 438-448. DOI: https:// doi.org/10.14483/21450706.13537 

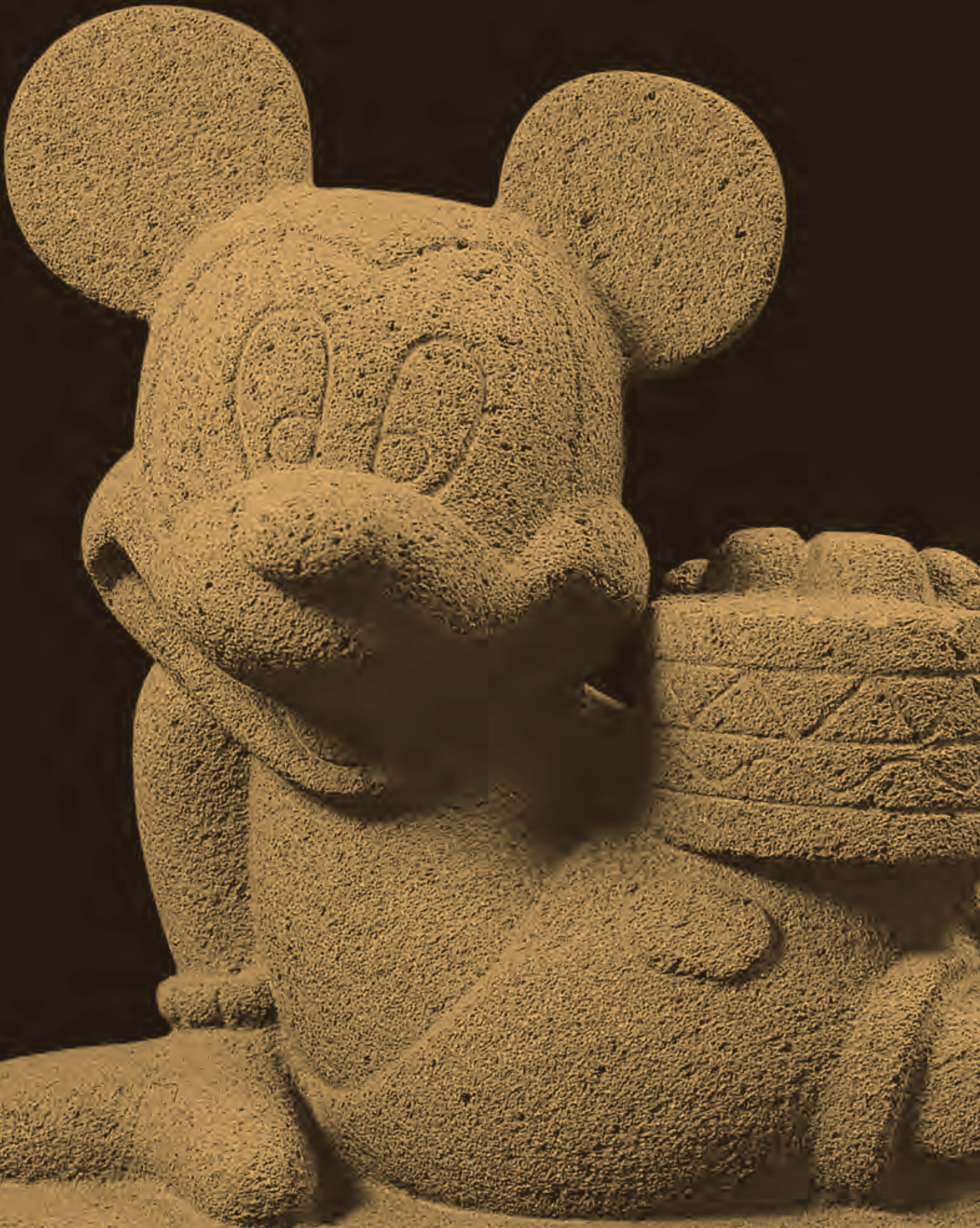

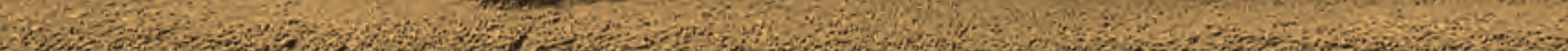

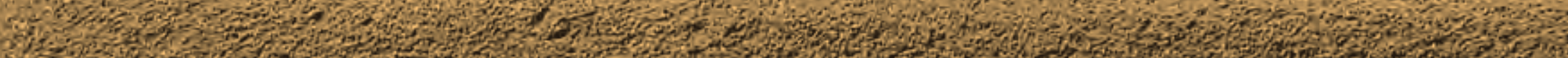

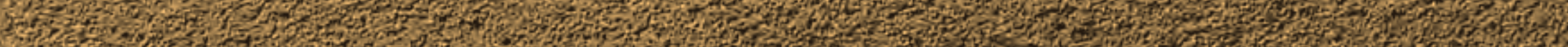

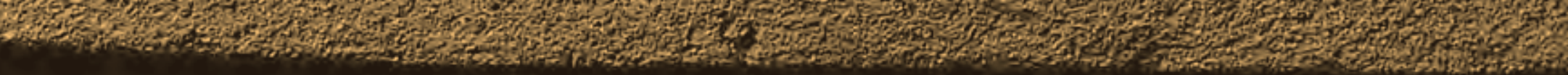


Mickey Mouse como símbolo de resistencia contra la contaminación cultural: una aproximación a la obra Chac Mool III de Nadín Ospina

\title{
Resumen
}

El presente artículo presenta algunas reflexiones teóricas sobre el uso de los medios de comunicación como articuladores ideológicos dentro de las sociedades de control (Deleuze, 1991) y la obra de arte como posibilidad de resistencia contra el poder (Deleuze, 2007), para con base en dichas posturas abordar la obra Chac Mool III (1999) del colombiano Nadín Ospina, en donde se evidencia la apropiación del artista de un icono cultural estadounidense (Mickey Mouse) para convertirlo en un contra discurso que cuestiona la contaminación cultural hegemónica.

\section{Palabras claves}

Nadin Ospina, colonialismo cultural, resistencia cultural, sociedad de control.

Mickey Mouse as a symbol of eesistance against cultural pollution: an approach to Chac Mool III by Nadín Ospina

\author{
Abstract \\ This article presents some theoretical reflections on the use of the media as ideological \\ articulator within control societies (Deleuze, 1991) and the work of art as a possibility of \\ resistance against power (Deleuze, 2007). Based on these positions, it addresses the work Chac \\ Mool III (1999) by Nadín Ospina, where the Colombian artist's appropriation of an American \\ cultural icon (Mickey Mouse) to make it a counter-discourse tool that questions hegemonic \\ cultural contamination is evident.
}

\section{Keywords}

Nadin Ospina, cultural colonialism, cultural resistance, control society.

Mickey Mouse comme un symbole de résistance contre la pollution culturelle : Une approche de l'ceuvre Chac Mool III de Nadín Ospina

\author{
Résumé \\ Cet article présente quelques réflexions théoriques sur l'utilisation des médias comme \\ articulateurs idéologiques dans les sociétés de contrôle (Deleuze, 1991) et de l'œuvre d'art \\ comme possibilité de résistance contre le pouvoir (Deleuze, 2007). Sur la base de ces positions \\ on adresse l'œuvre Chac Mool III (1999) du Colombien Nadín Ospina, où l'appropriation par \\ l'artiste d'une icône culturelle américaine (Mickey Mouse) pour en faire un contre-discours qui \\ interroge la contamination culturelle hégémonique est évidente.
}

\section{Mots clés}

Nadin Ospina, colonialisme culturel, résistance culturelle, société de contrôle.

Mickey Mouse como símbolo de resistência à poluição cultural: Uma abordagem da obra Chac Mool III por Nadín Ospina

\section{Resumo}

Este artigo apresenta algumas reflexões teóricas sobre o uso da mídia como articulador ideológico dentro das sociedades de controle (Deleuze, 1991) e da obra de arte como uma possibilidade de resistência ao poder (Deleuze, 2007), para com base em Nessas posições abordar a obra Chac Mool III (1999), do colombiano Nadín Ospina, onde a apropriação do artista de um ícone cultural americano (Mickey Mouse) para torná-lo um contra-discurso que questiona a contaminação cultural hegemônica é evidente. 


\section{Palavras chaves}

Nadin Ospina, colonialismo cultural, resistência cultural, sociedade de controle.

Mickey Mouse Nikakumi mana katisinama kawanakusunchi ukumanda jirikunata llugsichisunchi Chac Mool III de Nadin Ospina

\section{Maillallachiska:}

Maipi nukanchi kaskapi iukanchimi Nukanchipa pacha mama kawanga aidachinga Achka wata Ilukangapa Ilaku, waira, indi, sachuku, Tukui Nukanchipa, (Deleuze. 2007) mama alpa ruraska chimanda kami Chac Mool III (1999) ajai ministidu allilla iuarispa kawangapa. Colombianope Nadin Ospina icono culturalpe (Mickey Mause) ruraspa kawachispa.

\section{Rimangapa Ministidukuna:}

Nadin Ospina runa chasa suti, pakunapa kausai, kausaita sinchiachispa, tukuikunata kawaspa. 


\section{Introducción}

El presente texto aborda la obra Chac Mool III del artista colombiano Nadín Ospina ${ }^{1}$. En ella, Ospina se apropia de un icono cultural norteamericano para convertirlo en una obra de resistencia contra la contaminación cultural hegemónica. Para ello, sigo los postulados de Deleuze sobre las sociedades de control (1991) y la obra de arte como posibilidad de resistencia contra el poder (2007). Primero se hace una descripción de la obra, posteriormente se trata de establecer cómo Walt Disney y sus productos, como parte de la industria cultural y económica, son vehículos ideológicos dentro de la sociedad de consumo y colonialismo cultural, como lo demuestran Ariel Dorfman y Armand Mattelart en su libro Para leer al Pato Donald (1972) y Giroux en su libro The Mouse that Roared: Disney and the End of Innocence (1999). Se establecen filiaciones entre Ospina y el Pop Art, se analiza el paratexto del título y las relaciones intericónicas entre Mickey Mouse y el precolombino Chac Mool para develar los mecanismos retóricos a través de los cuales el artista construye un discurso de resistencia apropiándose de un símbolo imperialista para denunciar la contaminación cultural en detrimento de las identidades culturales latinoamericanas.

\section{Control y resistencia}

Hitler y el nacional-socialismo hicieron un manejo eficiente de la publicidad y de los medios hasta el punto de tener un ministerio de ilustración pública y propaganda con el cual expandieron sus ideas sobre el racismo, antisemitismo y antibolshevismo. Ya el mundo conoce sus secuelas.

El 5 de febrero de 2003, Colin Powell, Secretario de Estado de EE.UU., se disponía a dar una rueda de prensa para justificar el ataque a Irak en la sala del Consejo de Seguridad en la sede de la ONU. De un momento a otro, ordenaron posponer la transmisión por T.V. y cancelaron por unas horas el evento. La razón, a la entrada de la sala pendía una reproducción del Guernica, obra

\footnotetext{
1 Nadín Ospina es un artista pop y pintor colombiano, nacido en Bogotá en el año de 1960. Es reconocido principalmente por elaborar figuras basadas en el arte precolombino con personajes de la cultura popular norteamericana. Ha expuesto individual y colectivamente desde 1981 en Colombia, EE.UU., Alemania, Australia, Brasil, Venezuela, Cuba, México, España, Holanda, Noruega y Dinamarca. Ganador del XXXIV Salón Nacional de Artistas de Colombia en 1992 por In partibus infidelium; becario de la Fundación Guggenheim (1997).
}

de Picasso contra los horrores de la guerra. Un asesor recomendó cubrir la obra con un manto azul por considerar inconveniente dar ese discurso con esta obra como marco, lo que generó la inusitada demora.

Los casos anteriores ejemplifican los dos puntos que me interesa abordar. En primer lugar, el uso de los medios de comunicación como dispositivos de control ideológico y en segundo lugar, el arte como posibilidad de resistencia al poder, pues como quedó demostrado, el Guernica logró detener por unos instantes el llamado a la guerra de la nación más poderosa del mundo.

Gilles Deleuze en Posdata sobre las sociedades de control (1991) recuerda los estudios de Foucault que sitúa a las sociedades disciplinarias en el siglo XVIII y XIX, en donde el orden social se construía a través de una red de dispositivos o aparatos que producían y regulaban las costumbres, los hábitos y prácticas productivas. Eso se lograba asegurando la obediencia a sus reglas y a sus mecanismos de inclusión y/o exclusión, por medio de instituciones disciplinarias como la prisión, la fábrica, el asilo, el hospital, la universidad, la escuela, entre otras, sancionando y señalando los conductas y actuaciones normales y/o desviadas.

Para Deleuze las "sociedades de control" reemplazan a las "sociedades disciplinarias", recuperando el concepto de "control", inspirado en El almuerzo desnudo, de William Burroughs. Los encierros son moldes, pero los controles son modulaciones, maquinarias de producción de miedos y de dispositivos para enfrentarlos. Para vigilar ya no se requiere el encierro, y la espectacularidad del castigo ya no se ejerce sobre el cuerpo sino a través de los medios de comunicación. Se pasó de moldear los hábitos del cuerpo a modular los hábitos de la mente, definido por Lazzarato (2006, p. 100) como "subjetividades controladas".

Los medios de comunicación crean y administran consensos y pautas de comportamiento colectivo, convirtiendo la sociedad en una masa. Hoy nos encontramos frente a un "paisaje mediático" (Appadurai, 1990, pp. 41-61), entendido este como la distribución del equipamiento electrónico para la producción y la diseminación de la información en forma de imágenes del mundo, producidas y puestas en circulación en función de intereses públicos y privados, en donde la mercancía cultural, la política y las noticias se mezclan de manera indiscriminada, generando confusión entre realidad y ficción, pues los sujetos tienen en su mente realidades ficticias, incompletas, fragmentadas o 


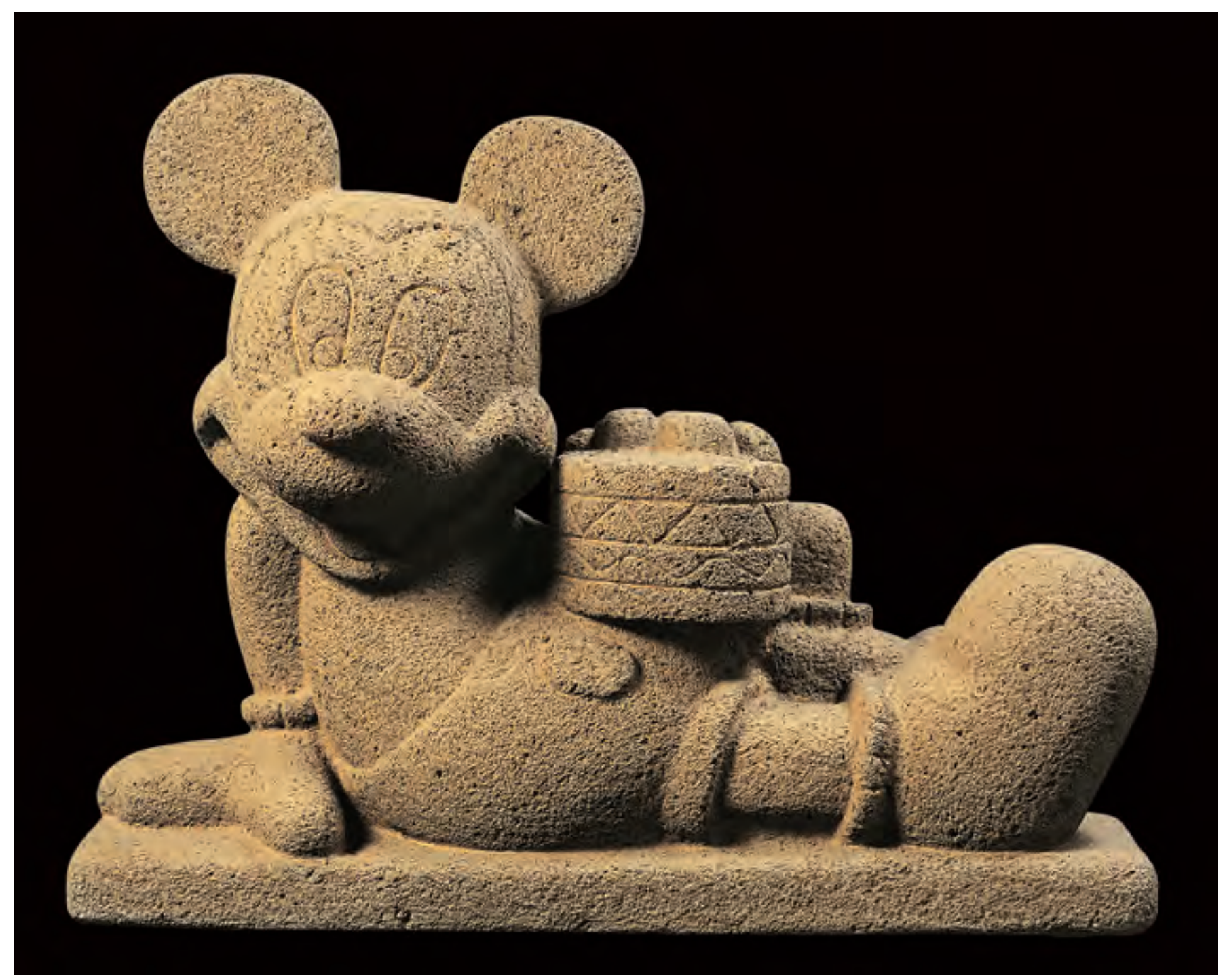

Imagen 1. Nadín Ospina (1999). Chac Mool III. Piedra tallada, 47 × 59 ×27 cm. Serie de 4. Colección particular, Bogotá, Colombia. L.C. Imagen cortesía del artista.

exageradas, originadas en la información que transmiten los medios masivos de comunicación. La audiencia y/o el público no tiene contacto con la realidad que les presentan y por lo tanto, no pueden verificarla, creyendo y habitando ciegamente en la imagen del mundo proyectada a través de la televisión, el internet, la radio, el cine y la prensa. Para Jean Baudrillard (1978) esta mutación de la realidad en "hiperrealidad" se presenta como una simulación. La imagen ya no representa la realidad, sino que constituye la realidad misma. No se conoce la realidad sino una imagen de la realidad. Estos discursos codificados, según Burroughs (2009, p. 72), tienen características del virus. Pues los sujetos están manipulados y transformados por procesos de contaminación. El lenguaje actúa como un virus que se reproduce con velocidad y facilidad, condicionando las diferentes actividades humanas.
Está claro que en estas épocas los dueños del poder económico, social y político crean imágenes del mundo que reproducen a través de los medios de comunicación, y que la imagen es tan fuerte que termina enajenando al ser humano, es decir, se convierte en el principal dispositivo de control. El dominio de las imágenes siempre ha estado en poder de la iglesia, el estado y ahora los medios de comunicación, alimentados por el capitalismo como sistema económico.

Deleuze (2007) dice que el arte se presenta como una posibilidad de resistencia contra el poder. No como contra-información sino como resistencia. Recuerda que en las dictaduras y en regímenes crueles como en el nazi, muchos logran escapar y traer contra-información, pero generalmente esa contra información no sirve de mayor cosa, salvo que derive en un acto 
de resistencia y la resistencia, no es ni información ni contra-información.

Malraux desarrolla un bello concepto filosófico, él dice una cosa muy simple sobre el arte, dice que es la única cosa que resiste a la muerte. [...] Se podría decir entonces, al menos esto, desde el punto de vista que nos ocupa, que el arte es lo que resiste, aun si no es la única cosa que resiste. De allí la relación tan estrecha entre el acto de resistencia y la obra de arte. No todo acto de resistencia es una obra de arte aunque, de una cierta manera, lo sea. No toda obra de arte es un acto de resistencia y sin embargo, de una cierta manera, lo es (Deleuze, 2007, p. 288).

Este "compromiso" no le quita su razón de ser obra de arte, pues siguiendo a Heidegger (1935), la obra de arte es en verdad una cosa confeccionada, pero dice algo otro que la simple cosa. La obra hace conocer claramente lo otro, revela lo otro, es alegoría.

Así como el poder cambió las formas de dominio, integrando la imagen como su principal aliada, las formas y estrategias de resistencia deben cambiar. El arte se presenta como una posibilidad de resistencia cultural. Por ende, algunos artistas se han apropiado de los mismos mecanismos de control, de los discursos hegemónicos y han instrumentalizado los símbolos del capitalismo, re-semantizándolos, re-configurándolos, re-escribiéndolos, para generar imágenes de resistencia como es el caso de Harun Farocki y Alfredo Jaar.

\section{Descripción de la obra}

La obra consiste en una estatua tallada en piedra de color gris, corrugada, con características antropomórficas y zoomórficas. Se halla en una postura decúbito supino, con las piernas semiflexionadas y parte del torso levantado, el rostro girado hacia un lado sostiene sobre el abdomen una vasija. La etiqueta señala la autoría, el título, el material y las dimensiones: Nadín Ospina. Chac Mool III. 1999. Piedra tallada, 47 × 59 × 27 cm. Serie de 4.

\section{Aproximación a la obra}

Disfrazado de entretenimiento para niños, Walt Disney como industria cultural y económica y sus "inocentes personajes animados, realizan operaciones de condicionamiento político, cultural e ideológico, que se inducen por asociación y mimetismo, inoculando valores y comportamientos desde la infancia para adoctrinar a los hombres del mañana que harán parte del engranaje de la sociedad de consumo. Estos dibujos animados fortalecen la ideología capitalista, valorando actos como la astucia, la avaricia, la frivolidad, y la violencia, como lo demuestran Ariel Dorfman y Armand Mattelart en su libro Para leer al Pato Donald (1972), quienes desde una postura marxista, plantean que las historietas de The Walt Disney Company no solo son un reflejo pasivo de la ideología capitalista e imperialista sino que además son metáforas del pensamiento burgués, medios, cómplices, instrumentos en el mantenimiento y difusión de dicha ideología que penetra desprevenidamente en la mente de los niños. Los autores destacan la falta de discreción de los guionistas a la hora propagar esta mentalidad:

Esto significa, como hemos visto, la división del mundo en espíritu y materia, en ciudad y campo, en metropolitano y buen salvaje, en monopolistas de la fuerza mental y monosufrientes de la fuerza corporal, en moralmente flexibles y moralmente inmóviles, en padre y niño, en autoridad y sumisión, en riqueza merecida y pobreza igualmente merecida. Por lo tanto, estas historietas son recibidas por los pueblos subdesarrollados como una manifestación plagiada del modo en que se les insta a que vivan y el modo en que efectivamente se representan sus relaciones con el polo central (Dorfman y Mattelart, 1972, p. 157).

En casi todas las películas y animaciones de Disney se presenta un orden social establecido, jerarquizado, aceptación de la subordinación, discriminación de personajes, estereotipos de belleza, y la violencia se muestra como algo natural, que la merecen los "malos", insensibilizando la angustia y la repulsión. La mujer es sumisa y obediente, orientada al amor y al matrimonio, de lo contrario es "la mujer malvada", la bruja. Queda claro que Mickey Mouse, como insignia de la industria cultural de Walt Disney, ha sido un vehículo de control ideológico para las sociedades de consumo.

La obra de Nadín Ospina es una representación de Mickey Mouse, personaje ficcional con rasgos antropomórficos y zoomórficos, creado por Walt Disney y que vio la luz el 18 de noviembre de 1928 en la película Steamboat Willie, exhibida en el cine Colony de Nueva York. También es conocido simplemente como Mickey, y en español Ratón Miguelito, o Ratón Mickey. Está 
protegido por derechos de autor y como marca registrada por The Walt Disney Company. Mickey es un icono que representa un inocente ratón, pero a su vez es considerado como un símbolo del mercantilismo cultural y del imperialismo norteamericano como lo afirma Giroux en su libro The Mouse that Roared: Disney and the End of Innocence (1999). La figura de Mickey Mouse hace parte de la cotidianidad occidental. Está en todas partes: impresa en ropa, cosméticos, juguetes, programas de tv, etc., es una imagen de superficie que tiene todo un proceso de reconocimiento y hábitos de consumo. Es una especie de implante nemotécnico, asumido por el espectador-consumidor, que de tanto verlo pasa desapercibido y pierde capacidad de generar nuevos sentidos. Es claro que el estudio de Dorfman y Mattelart se hizo sobre historietas y en los años 70, lo cual genera contextos históricos diferentes, sin embargo Giroux, en pleno cruce del milenio, sigue enfatizando sobre Disney como símbolo del imperialismo. Lo que interesa es demostrar que la imagen de los personajes de Disney como símbolos del colonialismo cultural es diacrónica y sincrónica.

Nadín Ospina recurre a la apropiación, término acuñado por el crítico de arte Douglas Crimp, quien organizó la exposición "Pictures", entre septiembre 24 y octubre 29 de 1977, a la que invitó a artistas que no trabajaban con imágenes originales, sino que se apropiaban de imágenes de otros autores para jugar con ellas y crear una nueva obra. Se refiere a artistas que toman o se apropian de elementos de obras precedentes para crear una última obra completamente nueva en la que se re-contextualizan los elementos apropiados dándole un nuevo significado. Son muchas las formas de apropiación, la copia, el montaje, el reciclaje, el collage, el objeto "encontrado" y el apropiado como ready-made, el sampleo, la serialización, la cita, el copy and paste, la fragmentación, la reconstrucción, la manipulación, el ensamblaje, el reciclado, el rayado, el scratcheado, la remezcla, la hibridación, postproducción, el found footage, entre muchos otros. En todas estas técnicas el autor no trata de hacer pasar como propios ninguno de los elementos constitutivos de la obra apropiada, no se trata de un plagio. Cuando se cita la obra de otro se hace explícitamente para que el espectador entienda que la obra se refiere a otra, a modo de homenaje o como crítica. Se trata a fin de cuentas de generar nuevas formas de ver. En cualquier caso, el artista que mira al pasado en el que se inscribe y replantea una obra clásica con una mirada contemporánea, bien para afirmar, cuestionar, inquirir o recusar su técnica o su temática o bien para decir algo nuevo a través de una proposición plástica o visual nueva.
Ospina se filia con el Pop Art, movimiento artístico de los 60's que emplea imágenes u objetos de la cultura popular y de uso cotidiano, fundamentalmente relacionados con los medios de comunicación, para separarlos de su contexto original y otorgarles una nueva realidad, transformándolos en obras de arte. Así mismo, destacan el aspecto banal o kitsch de dichos elementos, esencialmente a través del uso de la ironía. Algunas de sus características fueron el rechazo del expresionismo abstracto, el lenguaje figurativo referido a las costumbres, ideas y apariencias del mundo contemporáneo, temas urbanos, la sociedad de consumo y los medios de comunicación como proveedores de temas, formas de tratamiento pictórico no tradicional y combinación de la pintura con objetos reales integrados en la composición de la obra, entre otros. Entre los artistas más reconocidos del Pop Art tenemos a Richard Hamilton, Jasper Johns, Roy Lichtenstein, Robert Rauschenberg y Andy Warhol, entre otros.

Ospina se apropia de dos iconos culturales que tienen históricamente cargas semánticas: por un lado, el Mickey como objeto de consumo, al haberse globalizado, es visto como una imagen imperialista norteamericana, y el Chac Mool, por ser precolombino, como una señal de lo autóctono, de la identidad latinoamericana.

El paratexto del título de la obra, Chac Mool III, actúa como un índice intertextual que admite relacionar la obra con ciertas figuras del mismo nombre de la arqueología mesoamericana precolombina (fundamentalmente México), que aparecen al principio del Período Posclásico principalmente en las zonas de Chichén Itza y Tula. Consiste en una figura con rasgos humanos, reclinada hacia atrás, con las piernas encogidas y la cabeza girada, en cuyo vientre descansa un recipiente circular o cuadrado. El nombre maya le fue asignado por Auguste Le Plongeon, significa "gran jaguar rojo", quien en sus excavaciones en Chichén Itzá encontró una de estas esculturas y la trasladó a Mérida a finales de 1874. Hay diversas posturas sobre su representación y función, pero siempre han sido encontradas en contextos sagrados, en altares en el que se colocaban las ofrendas a los dioses o como lugar de sacrificios. Para algunos podría representar un guerrero tolteca por su indumentaria similar a la de los atlantes: está armado, pectoral de mariposa, un navajón atado en el brazo. Para las culturas precolombinas mexicanas el Chac Mool era el dios de la lluvia: Tláloc (en náhuatl clásico: Tlālōc; AFI ['tła:lo:k]) (náhuatl: Tláloc, "néctar de la tierra", de tlalli, tierra y octli, néctar"). 


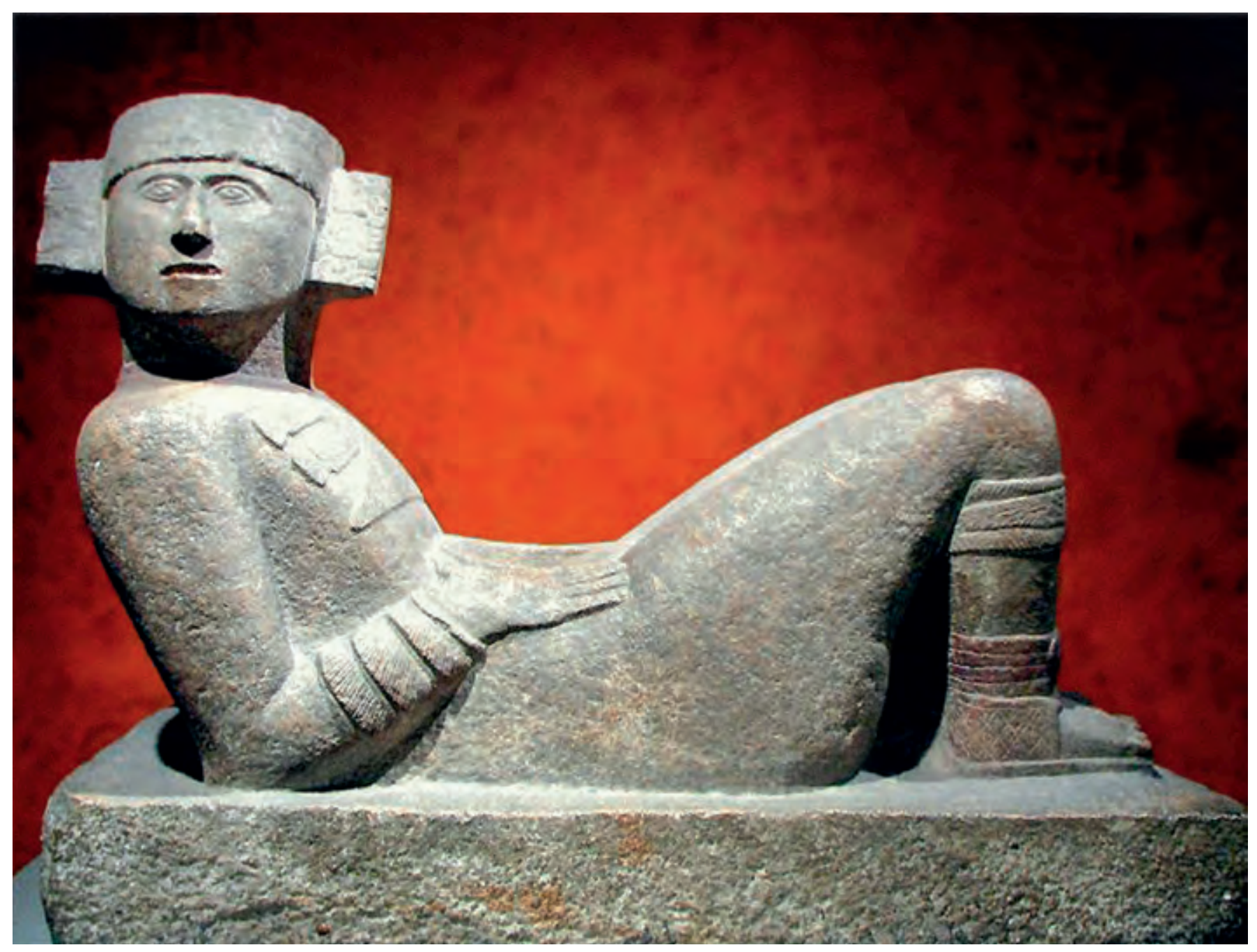

Imagen 2. Maya, Chac Mool. Fotografía: Luis Alberto Melograna. Fuente: http://www.flickr.com/photos/lecuna/1803450903/

Otro elemento de intertextualidad que se observa en el nivel connotativo del esteticismo que utiliza Ospina, es apelar a la técnica artesanal de la talla de la piedra, terminados rústicos, colores naturales, es decir, no se recurre a moldes o vaciados industriales, lo que permite un mayor grado de verismo al obedecer cierta tradición semántica de los tótems sagrados. Este soporte nos remite a una época de la humanidad: el periodo precolombino.

Es claro que la estatua de Mickey Mouse recrea la misma posición corporal en la obra de Ospina que la ostentada por Tláloc en los tallados precolombinos. Las características hibridas o intericónicas conllevan a formar una idea sobre la autoría de la obra y las intenciones, a partir de un infrasaber icónico con relación a las otras figuras iconográficas que hacen parte de la producción artística de Nadín Ospina, en donde el artista relaciona iconos contemporáneos con símbolos míticos precolombinos. Es usual que Ospina realice híbridos entre iconos de la cultura estadounidense y la estatuaria precolombina como una forma de reconfiguración y apropiación como respuesta y contra discurso a la imposición de los imaginarios, discursos y modelos "yanquis". Crítica que también expone el desplazamiento de los dioses míticos por unos nuevos dioses, los del capitalismo.

En la obra objeto de nuestro análisis, notamos cualidades icónicas que se manifiestan en representar a un objeto en virtud de sus cualidades o semejanzas con otro, en este caso lo concerniente a los materiales, colores y ciertas formas que la integran: gris, piedra tallada, postura física de la figura e idéntica nominación: Chac Mool. De la misma manera en que hay semejanzas entre una figura y la otra, también hay notables diferencias, pues la figura antropomórfica y zoomórfica de Ospina no se corresponde con el dios de la lluvia Tláloc sino con la figura de Mickey Mouse. El artista genera una iconicidad doble. Representa a dos objetos 
totalmente distintos en cuanto a sus significados, materialidades y formas: Tláloc y Mickey Mouse. Al primero, por la semejanza con los materiales, su postura, su nombre, textura y color. Al segundo por su forma física (las mismas orejas, nariz, cuerpo y ropa). Hay entonces en la obra de Ospina dos imágenes regidas por la antítesis, la antinomia y el dualismo. Se presenta antagonismo entre las imágenes a las que el imaginario individual o colectivo atribuye valores positivos o negativos. Se despliega una doble negación, el Mickey anula al Tláloc y viceversa. El precolombino se hace contemporáneo, se actualiza, pero a su vez el Mickey hace desaparecer el precolombino. Es como una tensión entre pasado y presente, en donde al afirmar lo uno se niega a lo otro. El espectador previsiblemente se va desestabilizar al consumir el objeto de una manera nueva.

La institucionalidad, el poder, lo hegemónico, reprime, oculta o invisibiliza todo lo que le es contrario. Una de las estrategias interesantes en la obra de Ospina es que oculta el precolombino con un icono capitalista, como sucede en la vida real, sin embargo, al llevarlo al plano del arte, se logra el efecto contrario: visibiliza lo invisibilizado, afirma negando. Ese no aparecer se presenta como una huella de lo que antes estuvo, generando conciencia de lo ausente, de lo que ha sido eclipsado, de lo invisibilizado. Al desmaterializar al Chac Mool se logra trascender lo material. Una desocultacion, como lo define Azúa: "vuelve del olvido lo ocultado. Es lo no-olvidado, lo no-perdido, lo no-oculto, y por lo tanto es "verdadero" aquello que se presenta ante nuestros ojos" (2002, p. 132).

El Chac Mool, representa al pasado y a las culturas precolombinas, Mickey se erige como representación del presente y de la cultura estadounidense. Hay una inversión de valores, el Chac Mool pierde su carácter sagrado y se vuelve un objeto comercial, profano. Mickey se entroniza y adquiere un valor sagrado, esto es, una condición de alteridad. Lo periférico pasa al centro y el centro queda en la periferia. Una resignificación de productos hegemónicos culturales y una puesta en crisis de la identidad de los pueblos marginales. No hay en la obra de Ospina la conciencia de una identidad individual y autónoma, independiente y diferente de la alteridad, por lo que al final, la aspiración máxima de la obra es la asimilación, la fusión, la disolución entre una figura y la otra. En este paso hay una unificación, una hibridación Chaac Mool/Mickey Mouse en la conciencia mediante un sentido de inversión de valores que genera un procedimiento de síntesis y armonización de los opuestos en una especie de oxímoron. En dicha metamorfosis, la figura del Chac Mool está ausente, invisibilizada, oculta; se da una conversión intericónica entre las figuras que transgrede el valor sagrado $\mathrm{y} / \mathrm{o}$ espectacular para erigirse como un nuevo símbolo de la colonización, de la contaminación cultural y de la pérdida de identidad de los pueblos latinoamericanos. Esta desmaterialización es lo que hace que el espectador reflexione.

\section{Conclusión}

La obra de Nadín Ospina llama la atención sobre la contaminación cultural hegemónica en deterioro de las identidades culturales latinoamericanas. Esto en gran medida por el avance del capitalismo, los TLC, el control de los medios y las comunicaciones, la globalización, entre otras. Mickey Mouse se presenta como símbolo de colonialismo al ser un ícono de la cultura estadounidense. Este personaje toma el puesto de Tláloc, dios de la lluvia e ícono de las culturas ancestrales mesoamericanas. Ambas figuras se hibridan adquiriendo características mutuas, sin embargo, la figura sagrada es invisibilizada por la imagen espectacular. Lo sagrado se profana y lo profano se sacraliza; recontextualizándose y reconfigurándose entre sí. Lo interesante en la estrategia de Ospina es que al invisibilizar el Chac Mool este aparece ante nuestra conciencia, desocultándose. El artista se apropia de un signo cultural capitalista para denunciar la pérdida de identidad de nuestros pueblos ante la invasión cultural hegemónica del imperialismo. Al develar las estrategias creativas y estéticas que usó Ospina para convertir un signo en contra-signo, se aprecia ciertas relaciones entre esta obra y varios contra-monumentos ${ }^{2}$. Aunque no es el objeto de este artículo, quiero destacar la similitud en las estrategias discursivas con contra-monumentos como el Monumento contra el fascismo (1986-1996), de Jochen Gerz y Esther Shalev-Gerz, que denunciaba cómo la tragedia representada figurativamente, se gasta, cansa, perdiendo el valor simbólico y de representación. El monumento, una columna de acero galvanizado cubierta de plomo se hundió en el suelo hasta quedar, apenas, un cuadrado al ras del suelo. Los artistas instalaron un mecanismo para que el monumento

\footnotetext{
2 Ante la inconformidad de que los monumentos siempre representan la historia oficial y dejan de lado la otra historia, la de los vencidos y los marginados, aparecen los contra-monumentos (concepto de James E. Young) siguiendo la idea de Foucault de contra-memoria, aquella que busca cuestionar y rechazar versiones oficiales de la historia impuesta por el poder o los historiadores.
} 
fuera enterrándose a razón de dos metros por año. Otro ejemplo es el Monumento contra el racismo y/o El monumento invisible (1993). Ubicado en Saarbruck, que consiste en 2.146 adoquines grabados y vueltos a ubicar boca abajo en la calle principal que lleva al castillo ocupado por los nazis durante la guerra. Los transeúntes no saben que existe un monumento bajo sus pies. Otro ejemplo es la Fuente invertida de Aschcott, en Kassel, Alemania. Estos monumentos y la obra de Ospina tienen estrategias en común como son la desmaterialización de un objeto para trascender lo material (El monumento invisible), pues al negar la materia aparece la idea; la elipsis se presenta como la ausencia, la no visibilidad o la no realización física de algo o de una parte, sin embargo, su no presencia o visibilidad está cargada de sentidos, como sucede con Tláloc cuando es invisibilizado. Por tanto, el cometido del espectador es llenar el vacío y dotarlo de significado.

\section{Referencias}

Appadurai, A. (1990). La modernidad desbordada. Dimensiones culturales de la globalización. Buenos Aires: FCE (2001).

Baudrillard, J. (1978). Cultura y simulacro. Traducido por Pedro Rovira. Editorial Kairós, Barcelona. 1977.

De Azua, F. (2002). Diccionario de las artes. Barcelona: Anagrama.

Deleuze, G. (2007). “¿Qué es el acto de creación?" En: Dos regímenes de locos. Textos y entrevistas. (19751995). Valencia: Pre-textos.

(1991). "Posdata sobre las sociedades de control" En: El lenguaje literario. Christian Ferrer (Comp.) Montevideo: Tomo 2. Ed. Nordan, 1991. Consultado en: http://www.fundacion.uocra.org/documentos/recursos/ articulos/Posdata-sobre-las-sociedades-de-control.pdf
Dorfman, A., y Mattelart, A. (2001). Para leer al Pato Donald (en castellano) (36.a edición). Buenos Aires: Siglo XXI.

Heidegger, M. (1935). El origen de la obra de arte. ler edición, Madrid: Alianza.

Katz, E., Blimler, J. G., y Gurevitch, M. (1986). “Usos y Gratificaciones de la comunicación de masas". En: Sociología de la Comunicación de masas. M. de Morgas (ed.), Barcelona: Gustavo Gilli.

Lazzarato, M. (2006). Políticas del acontecimiento. Buenos Aires: Editorial Tinta Limón.

Lippard, L. R., y Chandler, J. (1966). The Dematerialization of Art. Art international. 10(9), noviembre, pp. 28-40.

Mitri, C. "Los dibujos animados de Disney influyen en el Público Infantil" En: Creación y Producción en Diseño y Comunicación. 25(25), noviembre. Buenos Aires. Consultado en: http://fido.palermo.edu/servicios_dyc/publicacionesdc/vista/detalle_articulo. php?id_libro=138\&id_articulo=4643

Young, J. E. (1999). "Memory and counter-memory monument:the end of monument of Germany. Harvard design magazine. 9(otoño). pp. 1-10.

(1992). "The counter-monument: Memory

against itself in Germany today" En: Critical inquiry. 18. The University of Chicago, pp. 267-296. 